\title{
Evaluation of perinatal outcome in early and late pregnancy haemorrhage in tertiary care centre
}

\author{
Alka Patil ${ }^{1}$, Shruti Singh ${ }^{2}$, Rahul Patil ${ }^{3 *}$ \\ ${ }^{1}$ Professor and Head of Department, ${ }^{3}$ Senior Resident, Department of Gynaecology, ACPM, Dhule, Maharashtra, INDIA. \\ ${ }^{2}$ Consultant Gynaecologist, Department of Gynaecology, Indira IVF Centre, Delhi, INDIA. \\ Email: doctor.rvp@gmail.com
}

Abstract Aims and Objectives: ${ }^{1}$ To study perinatal outcome in early pregnancy hemorrhage.2)To study perinatal outcome in late pregnancy hemorrhage. Materials and Methods: 1. This is observational prospective study performed within span of 1 year (August 2014 to July 2015) in the Department of Obstetrics and Gynaecology in ACPM Medical college, Dhule. ${ }^{2}$ Total number of 200 women with bleeding per vaginal during pregnancy were enrolled in the study. The patients who presented with vaginal bleeding were divided into: ${ }^{1}$ Early pregnancy bleeding $<20$ weeks, 2 . Late pregnancy bleeding $>$ 20 weeks Since the demographic profile, etiology, risk factors involved, maternal and perinatal morbidities and mortalities associated with early and late pregnancy group are drastically different, so the cases in this study are divided into two groups - EARLY $(<20$ weeks) and LATE ( $>20$ weeks). Results: In this study, $66 \%$ patients presented with early pregnancy bleeding and $34 \%$ with late pregnancy bleeding. Perinatal outcome in Early pregnancy bleeding:- $30 \%$ spontaneous abortion, $7.6 \%$ preterm delivery, $4.5 \%$ IUGR. Perinatal outcome in Late pregnancy bleeding:- $3 \%$ stillbirth, $14.7 \%$ IUGR, $5.9 \%$ IUD, $58.8 \%$ preterm birth, $2.9 \%$ early and late neonatal deaths. Conclusion: Vaginal bleeding at any stage of pregnancy is an alarming event and can be potentially life- threatening to mother and fetus. Obstetrician should ensure that patient delivers in a well equipped centre with NICU facilities and expertization of neonatologist.

Key Word: haemorrhage.

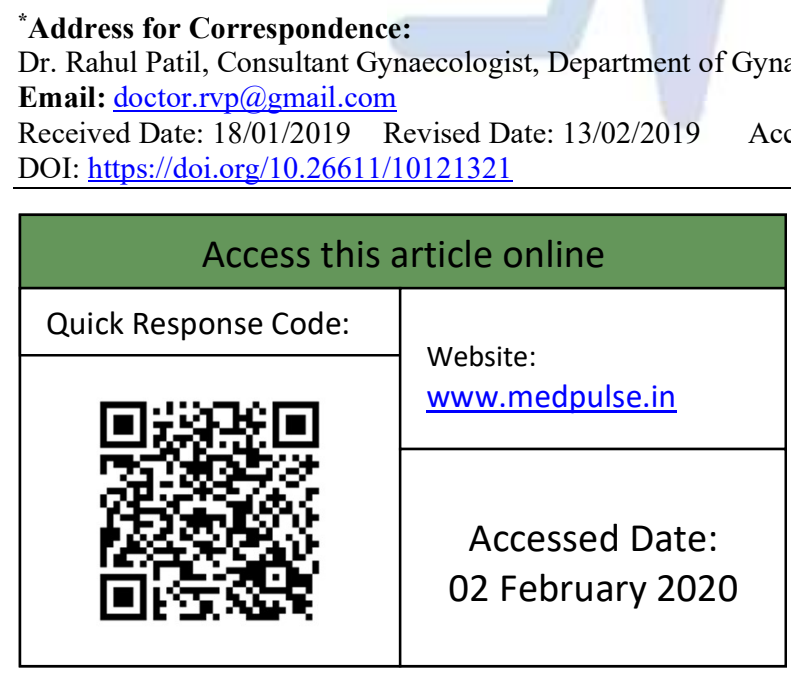

\section{INTRODUCTION}

Pregnancy is an important but potentially stressful time in a woman's life. When an unexpected, potentially dangerous event such as vaginal bleeding occurs, it is extremely upsetting for the expectant mother and father. While the obstetrician may not always be able to bring good news to these patients, in many cases early intervention can make the difference between life and death for the fetus, and at times the mother as well. Resuscitation of the mother, fetal monitoring, fetal gestational age estimates, an ultrasound to rule out previa as a cause, and obstetrical consultation should be performed in all cases. Early paediatric consultation is also essential when dealing with a viable fetus. Causes of early pregnancy bleeding: Haemorrhage in early pregnancy may be caused by abortion, ectopic pregnancy, trophoblastic disease, cervical carcinoma. It may be caused by pedunculated fibroid, cervical mucus polyp, cervical erosion or vulvar and vaginal lesions. Spotting in the first trimester may be a prelude to haemorrhage in the third trimester. ${ }^{1}$ Vaginal bleeding after midpregnancy is associated with maternal and fetal risks. Maternal morbidity may be caused by acute hemorrhage and operative delivery, and the fetus may be compromised by uteroplacental insufficiency and premature birth. ${ }^{2}$ Causes of late pregnancy bleeding: Placenta pravia Abruptio 
placentae Distal genital tract/ gynaecological bleeding Abnormal placentation Abnormal placental shape Vasa previa $^{3}$ In this study perinatal outcome in early pregnancy hemorrhage and late pregnancy hemorrhage are analysed.

\section{AIMS AND OBJECTIVES}

1. To study perinatal outcome in early pregnancy hemorrhage.

2. To study perinatal outcome in late pregnancy hemorrhage.

\section{MATERIALS AND METHODS}

This is observational prospective study performed within span of 1 year (August 2014 to July 2015) in the Department of Obstetrics and Gynaecology in ACPM Medical college, Dhule. Total number of 200 women with bleeding per vaginal during pregnancy were enrolled in the study.

The patients who presented with vaginal bleeding were divided into:

1. Early pregnancy bleeding $<20$ weeks

2. Late pregnancy bleeding $>20$ weeks

\section{Inclusion criteria}

- Women carrying a singleton gestation.

- Planned to deliver at the study site.

- Women intended to carry pregnancy to term.

\section{Exclusion criteria}

- Women carrying multiple gestation.

- Women using assisted reproductive technologies to conceive

- Women not intending to carry pregnancy to term.

\section{OBSERVATIONS AND RESULTS}

\begin{tabular}{cccc}
\multicolumn{2}{c}{ Table 1: Incidence of pregnancy affected by vaginal bleeding } \\
\hline \multirow{2}{*}{ Total ANC Admission } & No. of Cases with & \multicolumn{3}{c}{ Incidence } \\
& ANC Bleeding & $\%$ & Per 1000 \\
\hline $\mathbf{1 1 2 6}$ & $\mathbf{2 0 0}$ & $\mathbf{1 7 . 8}$ & $\mathbf{1 7 8}$
\end{tabular}

Approximately 1 in every 6 pregnancies is affected with vaginal bleeding.

\begin{tabular}{cccc}
\multicolumn{4}{c}{ Table 2: Incidence of vaginal bleeding } \\
\hline & No. of Cases (\%) & \multicolumn{2}{c}{ Incidence } \\
$\%$ & Per 100 \\
\hline $\begin{array}{c}\text { Early Pregnancy } \\
\text { (<20 weeks) } \\
\text { Late Pregnancy } \\
\text { ( }>20 \text { weeks) }\end{array}$ & $\begin{array}{c}132(66 \%) \\
68\end{array}$ & 11.7 & 117 \\
\hline
\end{tabular}

Since the demographic profile, etiology, risk factors involved, maternal and perinatal morbidities and mortalities associated with early and late pregnancy group are drastically different, so the cases in this study are divided into two groups- EARLY ( $<20$ weeks) and LATE ( $>20$ weeks), and studied separately in terms of perinatal outcome.

Table 3: Distribution of cases according to age of patient

\begin{tabular}{ccc}
\hline Age (Years) & No. $(\mathrm{n}=\mathbf{2 0 0})$ & $\%$ \\
\hline$<20$ Years & 8 & 4 \\
21-25 Years & 64 & 32 \\
26-30 Years & 78 & 39 \\
31-35 Years & 44 & 22 \\
$>35$ Years & 6 & 3 \\
\hline
\end{tabular}

Maximum number of cases were concentrated in 26 - 30 years of age with mean age of 28 years.

Table 4: Distribution of cases according to gravidity

\begin{tabular}{ccc}
\hline GRAVIDA & No. & $\%$ \\
Primi & 84 & 42 \\
Multi & 116 & 58 \\
\hline
\end{tabular}

Maximum number of cases were multigravida.

\begin{tabular}{|c|c|c|}
\hline & No. & $\%$ \\
\hline Booked & 33 & 25 \\
\hline Unbooked & 99 & 75 \\
\hline
\end{tabular}


Table 6: ANC care of late pregnancy bleeding

\begin{tabular}{ccc}
\hline & No. & $\%$ \\
\hline Booked & 30 & 44.1 \\
Unbooked & 38 & 55.9 \\
\hline
\end{tabular}

Majority of cases were unbooked and booking status was minimal especially with early bleeding group.

\begin{tabular}{|c|c|c|c|}
\hline \multicolumn{2}{|r|}{ DIAGNOSIS } & \multirow{2}{*}{$\begin{array}{l}\text { No. } \\
40\end{array}$} & \multirow{2}{*}{$\begin{array}{c}\% \\
20\end{array}$} \\
\hline 1) & Abortions - Spontaneous & & \\
\hline 2) & Threatened Abortion & 56 & 28 \\
\hline 3) & Molar Pregnancy & 6 & 3 \\
\hline 4) & Ectopic Pregnancy & 14 & 7 \\
\hline 5) & Abruptio Placentae & 30 & 15 \\
\hline 6) & Placenta Previa & 33 & 16.5 \\
\hline 7) & Others:- & 21 & 10.5 \\
\hline
\end{tabular}

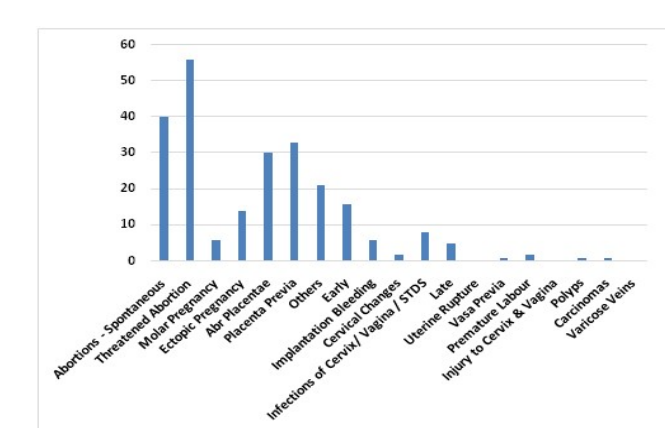

Various causes of vaginal bleeding during pregnancy are shown here. Maximum numbers of cases were of threatened abortion and minimum were of bleeding due to cervical changes in early pregnancy group. And among late pregnancy group, maximum cases were of placenta previa and minimum were of vasa previa, polyps and carcinoma.

Table 8: Gestational age at delivery in Early pregnancy bleeding

\begin{tabular}{ccc}
\hline GA & No. of Patients & $\%$ \\
\hline$>37$ Weeks & 44 & 33.3 \\
$<37$ Weeks & 28 & 21.2 \\
\hline
\end{tabular}

Table 9: Gestational age at delivery in Late pregnancy bleeding

\begin{tabular}{ccc}
\hline GA & No. of Patients & $\%$ \\
\hline$>37$ Weeks & 28 & 41.2 \\
$<37$ Weeks & 40 & 58.8 \\
\hline
\end{tabular}

In Late pregnancy bleeding group, preterm delivery rate was higher than term delivery.

Table 10: Perinatal outcome in Early pregnancy bleeding

\begin{tabular}{ccc}
\hline PERINATAL OUTCOME & No. & $\%$ \\
\hline Spontaneous Abortions & 40 & 30.3 \\
Preterm Delivery & 10 & 7.6 \\
Still Birth & 0 & 0 \\
NICU Admission & 2 & 1.5 \\
Neonatal Deaths & 0 & 0 \\
IUD & 0 & 0 \\
IUGR & 6 & 4.5 \\
Total No. of Deaths & 0 & 0 \\
Discharged Alive & 72 & 54.5
\end{tabular}

Approximately $30 \%$ cases ended up in spontaneous miscarriage and the ones which continued till period of viability had many adverse perinatal outcomes in the form of IUGR, preterm delivery and NICU admissions. 
Table 11: Perinatal outcome in Late pregnancy bleeding

\begin{tabular}{ccc}
\hline PERINATAL OUTCOME & No. & $\%$ \\
\hline Still Birth & 2 & 3 \\
IUGR & 10 & 14.7 \\
IUD & 4 & 5.9 \\
Preterm Birth & 40 & 58.8 \\
NICU Admission & 15 & 22 \\
Early and Late Neonatal & 2 & 2.9 \\
Deaths & 8 & 11.8 \\
Total no of Deaths & 60 & 88.2 \\
Discharged Alive &
\end{tabular}

Above table shows high number of perinatal mortality in cases with bleeding in late pregnancy, both in-utero and exutero. NICU admissions were also found to be high among these cases.

Table 12: One minute APGAR scores among gravidas with Early pregnancy bleeding :-

\begin{tabular}{ccc}
\hline APGAR Score & No & $\%$ \\
\hline $0-3$ & 5 & 6.9 \\
$4-6$ & 9 & 12.5 \\
$7+$ & 58 & 80.5 \\
\hline
\end{tabular}

Table 13: Five minute APGAR scores among gravidas with Early pregnancy bleeding

\begin{tabular}{ccc}
\hline Apgar score & No. & $\%$ \\
\hline $0-3$ & 0 & 0 \\
$4-6$ & 3 & 4.2 \\
$7+$ & 69 & 95.8 \\
\hline
\end{tabular}

Only 72 cases out of total 132 cases, with early pregnancy bleeding, survived the period of viability.

Table 14: One minute APGAR scores among gravidas with Late pregnancy bleeding

\begin{tabular}{ccc}
\hline APGAR Score & No & $\%$ \\
\hline $0-3$ & 15 & 22 \\
$4-6$ & 8 & 11.8 \\
$7+$ & 45 & 66.2 \\
\hline
\end{tabular}

Table 15: Five minute APGAR scores among gravidas with Late pregnancy bleeding

\begin{tabular}{ccc}
\hline APGAR Score & No & $\%$ \\
\hline $0-3$ & 8 & 11.8 \\
$4-6$ & 4 & 5.9 \\
$7+$ & 56 & 82.3
\end{tabular}

Due to perinatal asphyxia, most of the newborns had low APGAR scores at 1 and 5 minutes in late pregnancy bleeding cases as compared to early pregnancy bleeding group.

Table 16: Complications among the live newborns in Early pregnancy bleeding

\begin{tabular}{ccc}
\hline Complications & NO. & $\%$ \\
\hline Nicu admission & 2 & 2.8 \\
Sepsis & 1 & 1.4 \\
Convulsions & 1 & 1.4 \\
Rds & 1 & 1.4 \\
Hemorrhage & 0 & 0 \\
Jaundice & 1 & 1.4 \\
Hie & 0 & 0 \\
Congenital malformations & 0 & 0 \\
Death & 0 & 0
\end{tabular}

live newborns of early pregnancy bleeding group showed no significant increase in the complications as compared to late pregnancy bleeding group. 
Table 17: Complications among the live newborns in Late pregnancy bleeding

\begin{tabular}{ccc}
\hline Complications & No. & $\%$ \\
\hline NICU Admission & 15 & 22 \\
Sepsis & 10 & 14.7 \\
Convulsions & 3 & 4.4 \\
RDS & 5 & 7.3 \\
Hemorrhage & 1 & 1.5 \\
Jaundice & 10 & 14.7 \\
HIE & 1 & 1.5 \\
Congenital Malformations & 1 & 1.5 \\
Death & 2 & 2.9
\end{tabular}

newborns of late pregnancy bleeding group suffered from a variety of complications of preterm delivery and perinatal asphyxia and so the rate of nicu admissions was also higher.

\section{DISCUSSION}

Bleeding during pregnancy is a common clinical entity in our set- up. Whether occurring in early or later half of pregnancy, antenatal bleeding has significant impact on perinatal outcome. Distribution of various cases of bleeding during pregnancy reporting to our hospital shows the predominance of antepartum haemorrhage accounting for $31.5 \%$ of the cases, with an overall incidence of $5.6 \%$; which corroborates by Fouzia et al 2010. ${ }^{4}$ The high incidence of LPB, reported in this study, may be because of large number of referred cases to this tertiary care centre, but still this may be an underestimate of actual figure as many such patients fail to reach hospital in time or a multitude of cases do not report to any hospital at all. In EPB group, maximum number of cases were clustered in mothers of higher age group of 26 - 30 years ( $39 \%$ ). Similarly in LPB group, maximum number of cases $(48.3 \%)$ presented in age group of $26-$ 30 years with a mean of 20.01 years while Fouzia et al $2010^{4}$ reported a mean of 30 years, Savita et al $2008^{5}$ and Das et al $1975^{6}(26.8$ years each). Other studies reporting such higher incidence of LPB in multipara (around 5-8 times than that in primi) are- Gilliam et al $2002^{7}$,William et al $1993^{8}$, Ananth et al $1996^{9}$. Higher order parity was once again proved to be positive risk factor in LPB group (79.3\% in multipara in present study, 92.3\% in Fouzia et al $2010^{4}$ ),Savita et al $2008^{5}(63.01 \%)$. But this relation was not detected for EPB group. So, being a problem of multiparity, reduction in family size and the issues of contraception are highly applicable if this incidence has to be reduced. Majority of cases were unbooked, signifying the importance of ANC care and revealing the lacunae in the $\mathrm{MCH}$ care. Booking status was below the half level in EPB group (25\%). But in cases of LPB, this relationship was milder (44\%). This clearly shows the importance of antenatal care in prevention and early detection of antepartum haemorrhage to reduce morbidities and mortalities. There are studies that find normal postnatal development after threatened abortion (Buck et al $1969^{10}$ and Barker et al 1967'11).However, some of the studies find that the association between bleeding in early pregnancy and suboptimal outcome may be useful for detecting pregnancies at risk. This was suggested by Hobel et al $1973^{12}$ and Adelstein and Fedrickin $1978^{13}$. The various cases of EPB group comprised predominantly of threatened miscarriage $(28 \%)$, most of which crossed the period of viability with proper ANC care with favourable pregnancy outcome. The other important diagnosis were ectopic and molar pregnancies (7\% and 3\%) in EPB group. Placenta previa accounted for majority of cases in the late group (48.5\%) against abruption (44.1\%) and other causes (7.3\%). $21.2 \%$ of threatened miscarriage continuing beyond 24 weeks ended in preterm delivery and $58.8 \%$ of LPB group cases had the same outcome. This finding alone may be responsible for the other morbidities such as low birth weight, depressed 1 and 5 minute APGAR scores and increased perinatal mortality. Various other studies which have postulated the increased risk of pregnancy related complications (primarily due to placental dysfunction) in EPB group, such as placental abruption, preterm labour, IUGR, PPROM, LBW, CS are - Weiss et al $2004^{14}$, Patel et al $2000^{15}$, Alcazar et al $2000^{16}$, Das et al $1996^{17}$.Increased risk of placental abruption and IUGR could not be documented in present studies, but was reported by Mulik et al $2004^{18}$, Szekeres- Bartho et al $2002^{19}$. Double the risk of preterm delivery has been reported by William et al $1991^{20}$, Batzofin et al $1984^{21}$ in EPB group but was found to be mildly raised in our study (7.6\%).Although the incidence of stillbirths in EPB group was not significant in present study as contrary to other studies such as - Batzofin et al $1984^{21}$, Funderburk et al $1980^{22}$. Perinatal outcome observed during this study supports the evidence in literature that pregnancy bleeding (irrespective of GA) is an important and independent predictor of adverse perinatal outcome. The present study suggests that the greater risk to pregnancies affected by vaginal bleeding is premature delivery before 37 weeks (36\%). This factor alone may be responsible for other findings including LBW, depressed one and five minute APGAR scores and increased perinatal mortality. Other studies are - Savita et al $2008^{5}$ (41.8\%), Fauzia et 
al $2010^{4}(79.16 \%)$, Martha et $a^{23}(71 \%)$, Cotton et al $1980^{24}(77.5 \%)$. Many other studies have correlated threatened miscarriages with preterm delivery - Weiss et al 2004 ${ }^{14}$, Mulik et al 2004 ${ }^{18}$, Williams et al $1991^{20}$. Babies delivered as IUD and stillbirths in LPB group were found to be $5.9 \%$ and $3 \%$. (Fauzia et al $2010^{4}$ reported $42.1 \%$ fresh stillborns in APH bleeding ).Babies with IUGR and those requiring NICU admission in LPB group were $14.7 \%$ and $22 \%$ respectively. $2.9 \%$ had neonatal deaths ( early and late) and rest were discharged alive $(88.2 \%)$. Other studies reporting perinatal mortality in APB cases are - Fauzia et al $2010^{4}(50.2 \%)$, Savita et al $2008^{5}(23.7 \%)$, Arora et al $2001^{25}(61.5 \%)$, Khosla et al $1989^{26}(53.5 \%)$. The same complications were not significantly raised in the EPB group due to small sample size. Outcome of pregnancies affected by EPB ended in spontaneous abortion in $30.3 \%$ of cases, $7 \%$ were ectopic and $3 \%$ were molar pregnancy. The rest $34 \%$ cases progressed to viable pregnancy but major and minor complications involved. Newborns of LPB cases suffered from a variety of complications of pretem delivery and perinatal asphyxia. No significance association was observed between prevalence of congenital anomalies in either group, as also in other studies(Batzofin et al $1984^{21}$, Funderburk et al $1980^{22}$ ). With previous threatened miscarriages, pregnancy may be more complicated with preterm delivery, PPROM, lower birth weight. ${ }^{27-31}$ Study conducted by Sipila et al suggests that first and second trimester vaginal bleeding are important predictors of adverse neonatal outcomes. Both first and second trimester bleeding were associated with high fetal loss. ${ }^{32}$ Bleeding prolonged into the second trimester is likely to affect fetal outcome adversely. That limited to the first trimester may either end in abortion or (if not severe) may not affect fetal health unduly as enough recovery time is available. ${ }^{33,34}$ Study conducted by Evrenos et al indicates that women who have vaginal bleeding in the first trimester are at increased risks of later pregnancy complications; especially preterm delivery, shortened mean pregnancy period, lower gestational fetal weight and preterm rupture of membrane. ${ }^{27,28,35}$ Bleeding during first trimester was associated with increased risk of preterm delivery. ${ }^{29}$ Because of impaired implantation and invasive trophoblasts, spontaneous abortion may occur in early pregnancy while preterm delivery, PPROM, placental abruption and preeclampsia may happen in later period. ${ }^{28-}$ ${ }^{30}$ In a study conducted by Hossain et al preterm delivery and PPROM rates were increased in the threatened miscarriage group. ${ }^{18,29-31,36,37}$ Lower Apgar scores after 1 and 5 minutes were expected in threatened abortion group because of increased rates of preterm delivery. ${ }^{37}$ Strobinoand Silverman have linked frequency of low birth weight and preterm birth with the severity of maternal hemorrhage. ${ }^{38}$ The prognosis of abruptio placentae complications depends on whether treatment is received by the patient, on the quality of treatment, and on the severity of the abruption. Outcomes for the baby also depend on the gestational age. The prognosis on the fetus is worse, currently, in the UK, about $15 \%$ of fetuses die following this event. Without any form of medical intervention, as often happens in many parts of the world, placental abruption has a high neonatal mortality rate. ${ }^{39}$ The baby may be born as a low birth weight. The fetus may be deprived of oxygen and thus suffer from asphyxia. Placental abruption may also result in fetal death, or stillbirth. The newborn infant may have learning issues at later development stages, or even requiring professional aid. ${ }^{40}$ Thus, APH remains important because it is relatively frequent with potential adverse outcomes for the mother and the neonate. The high neonatal mortality and morbidity seen with APH is mostly due to its strong association with preterm delivery. ${ }^{41-43}$ Series of studies have demonstrated that APH is an independent factor for adverse neonatal outcomes in very preterm, as well as late preterm neonates. Among these groups APH has been independently associated with increased neonatal mortality and morbidity, particularly severe respiratory disorders, increased admission rate to NICU and increased hospital stay. ${ }^{44-47}$ In a study conducted by Johns $\mathrm{J}$ et al both preterm delivery and PPROM are related with low birth weight as predictable factors. Our study demonstrated that the fetal weight was lower in the case than control group. It is related with births at earlier gestations. ${ }^{37,48}$ In a study conducted by Yang J, Bleeding in both trimesters was associated with preterm birth due to preterm labor $(\mathrm{RR}=3.6,95 \% \mathrm{CI}: 1.9,6.8)$. Bleeding of multiple episodes, on multiple days, and with more total blood loss was associated with an approximate twofold increased risk of earlier preterm birth, PPROM, and preterm labor. In contrast, bleeding in the second trimester only, of a single episode, on a single day, and with less total blood loss was not associated with any category of preterm birth. ${ }^{49}$ Recurrent bleeding predicted preterm birth more strongly than did single episodes, consistent with previous studies, as stated by Williams et $a l{ }^{50,51}$ However, a series of studies have demonstrated that APH is an independent factor for adverse neonatal outcomes in very preterm, as well as late preterm neonates. Among these groups APH has been independently associated with increased neonatal mortality and morbidity, particularly severe respiratory disorders, increased admission rate to NICU and increased hospital stay. ${ }^{52-55}$ Some forms of placental dysfunction causes vaginal bleeding in late pregnancy (Alexander et al 2000) and are well established as causes 
of preterm birth (Tuzovic et al 2003). Including pregnancies complicated by placental abnormalities could account in part for the reported association between vaginal bleeding in the aggregate and preterm birth. ${ }^{54,55}$ Further insights regarding the association between vaginal bleeding and preterm birth are likely to come only from more detailed understanding of the underlying causes of the bleeding or more refined and complete assessment of bleeding characteristics. Beyond statistical prediction of preterm birth, the biologic and clinical meaning of this common pregnancy complication remains to be fully elucidated. ${ }^{49}$

\section{CONCLUSION}

Patient who had vaginal bleeding of any amount, in pregnancy, should be monitored vigilantly. Preparations should be made for premature delivery and measures taken to arrest premature labor as needed. Obstetrician should ensure that the patient delivers in a well- equipped centre where intrapartum and neonatal complications can be recognized and managed with neonatologists. Early recognition of risk factors for early and late pregnancy bleeding is essential. Whether occurring in early or later half of pregnancy, bleeding has significant impact on perinatal outcome. Pregnancy bleeding (irrespective of gestational age), is an independent predictor of adverse perinatal outcome.

\section{REFERENCES}

1. Wafaa Hassan, Munir Abu- Helalah, Abdul Salam. Incidence of early pregnancy bleeding in the Eastern region of Saudi Arabia. International Journal of Reproduction, Contraception, Obstetrics and Gynaecology. 2016 may; 5(5): 1392-1399.

2. Ellen Sakornbut, Lawrence Leeman, Patricia Fontaine. Late Pregnancy Bleeding. Am Fam Physician. 2007 Apr 15;75(8):1199-1206.

3. South Australian Perinatal Practice Guidelines: 29/04/13 cywhs.perinatalprotocol@health.sa.gov.au.

4. F Sheikh, S Khokhar, P Sirichand, R Shaikh. A Study of Antepartum Haemorrhage: Maternal And Perinatal Outcome. Medical Channel.April-June 2010. Volume 16, No 2.

5. Savita R S, Nymphaca, Smriti N. Maternal and perinatal outcome in antepartum hemorrhage: A study at a tertiary care referral institute. The Internet $\mathrm{J}$ of Gynaecology and Obstetrics.2008:vol 9; no.2

6. Das B. Antepartum hemorrhage in three decades. J Obstet Gynae India 1975,25:636-7

7. Gilliam M, Rosenberg D, Davis F. The likelihood of placenta previa with greater number of cesarean delivery and higher parity. Obstet Gynecol 2002;99(6):976-80.

8. William MA, Mittewdro PR. Increasing maternal age a determinant for placenta previa, more important than increasing parity? J Reprod Med 1993;38:425-8.

9. Ananth CV, Wilcox AZ, Savita DA, Bowes WA, Luther ER. Effect of maternal age and parity on the rise of uteroplacental bleeding disorders in pregnancy. Obstet Gynecol 1996;88:511-6.

10. Buck c, Gregg R, Stavarky K, et al. the effect of single prenatal and natal complications upon the development of children of mature birth weight. Pediatrics. 1969;43:942.PMID:5786218

11. Barker DJ, Edward JH. Obstetrics complications and school performance. Br. Med J. 1967;3:695. PMID: 5786218

12. Hobel, Tulchinsky. Plasma human chorionic gonadotrophin, estrone, estradiol, estriol, progesterone and 17alpha hydroxyl progesterone in human pregnancy. Early normal pregnancy. Amer j. obstet. Gynec. 1973; 117:884892.

13. Fedrick J, Adelstein P. factors associated with low birth weight of infants delivered at term. Br J. Obstet Gynaecol. 1978. Jan;85(1):1-7

14. Weiss JL, Malone FD, Vidaver J, Ball RH, Nyberg DA, Comstock $\mathrm{CH}$, et al. Threatened abortion: a risk factor for poor pregnancy outcome, a population-based screening study. Am J Obstet Gynecol 2004;190:745-50

15. Patel BI, Trivedi V. Threatened abortion outcome in relation to intrauterine clot site and not only volume. Inj J Gynecol Obstet 2000;70(4):D44

16. Alcazar JL, Ruiz. Uteroplacental circulation in patients with first trimester threatened abortion. Fert Steril.2000 Jan;73(1):130-135

17. Das AG, Gopalan S, Dhaliwal LK. Fetal growth and perinatal outcome of pregnancies continuing after threatened abortion. Aust N Z J Obstet Gynecol.1996 May;36(2):135-139

18. Mulik V, Bethel J, Bhal K. A retrospective populationbased study of primigravid women on the potential effect of threatened miscarriage on obstetric outcome. J Obstet Gynaecol. 2004 Apr;24(3):249-253

19. Julia Szekeres-Bartho. Immunological Relationship Between The Mother And The Fetus. International Reviews of Immunology Vol. 21 , Iss. 6,2002.471- 49

20. Williams MA, Mittendorf R, Lieberman E, Monson RR. Adverse infant outcomes associated with first-trimester vaginal bleeding. Obstetrics and gynecology. 1991;78(1):14-8.

21. Batzofin, .T.H., Fieding, W.L. and Friedman, A.E. Effect of vaginal bleeding in early pregnancy outcome. Obstet. Gynecol., 1984;63:515-8

22. Funderburk SJ, Guthrie D, Meldrum D. Outcome of pregnancies complicated by early vaginal bleeding. $\mathrm{Br} \mathrm{J}$ Obstet Gynaecol 1980;87:100-5

23. Martha W.F. Rac, MD, C. Edward Wells, MD, Diane M. Twickler, MD, Elysia Moschos, MD,Donald D. McIntire, $\mathrm{PhD}$, and Jodi S. Dashe, MD .Placenta Accreta and Vaginal Bleeding According to Gestational Age at Delivery. OBSTETRICS and GYNECOLOGY 1. VOL. 0, NO. 0, MONTH 2015.1-6

24. B. Cotton, David and A. Read, John and H. Paul, Richard and J. Quilligan, Edward. (1980). The Conservative Aggressive Management of Placenta Previa. American journal of obstetrics and gynecology. 137. 687-95.

25. Arora R, Devi U, Majumdar R. Perinatal morbidity and mortality in antepartum hemorrhage. J Obstet Gynae India $2001 ; 51(3) 102-4$ 
26. Khosla A, Dahiya V, Sangwan K, Rathor S. Perinatal outcome in antepartum haemorrhage. J Obstet Gyn India 1989; 9: 71-3

27. Evrenos A, Güngör A, Gülerman C, Cosar E. Obstetric outcomes of patients with abortusimminens in the first trimester. Arch Gynecol Obstet. 2014;289(3):499- 504. doi:10.1007/s00404-013-2979-5.

28. Lykke JA, Dideriksen KL, Lidegaard O, Langhoff-Roos J. First trimester vaginal bleeding and complications later in pregnancy. Obstet Gynecol. 2010;115(5):935- 944. doi: 10.1097/AOG.0b013e3181da8d38.

29. Hossain R, Harris T, Lohsoonthorn V, Williams M. Risk of preterm delivery in relation to vaginal bleeding in early pregnancy. Eur J ObstetGynecolReprod Bio. 2007;135(2):158-163. doi.org/10.1016/j. ejogrb.2006.12.003.

30. Hackney DN, Glantz JC. Vaginal bleeding in early pregnancy and preterm birth: systematic review and analysis of heterogeneity. J Maternal-Fetal Neonatal Med. 2011;24(6):778-86. doi:10.3109/14767058.2010 .530707.

31. Rosen T, Kuczynski E, O’Neill LM, Funai EF, Lackwood CJ. Plasma levels of thrombin- antithrombin complexes predict preterm premature rupture of the fetal membranes. J Maternal- Fetal Med. 2001;10(5):297-300. doi:10.1080/jmf.10.5.297.300.

32. Sipila. P., Oja, H. and Wendt, L. Perinatal outcome ofpregnancics complicated by vaginal bleeding. $\mathrm{Br}$. J.Obstet. Gynecol., 1992;99:959-63.

33. Chamberlain, G.V.P The epidemiology ofperinatal loss. In Studd, J. eds. Progress in Obstetrics and Gynaccology, Vol. 1, Edinburgh, Churchill Livingstone, 1981, p. 10.

34. Villar, J., Altobelli, L., Kestler, E. et al. A health priority for developing countries: The prevention of chronic fetal malnutrition. Bull. WHO., 1986;64:847-851.

35. Johns J, Jauniaux E. Threatened miscarriage as a predictor of obstetric outcome. Obstet Gynecol. 2006;107:845-850. doi:10.1097/01. AOG.0000206186.91335.9a.

36. Yang J, Savitz DA.The effect of vaginal bleeding during pregnancy on preterm and small for gestational age births:US National Maternal and Infant Health Survey, 1988. Paediatr Perinat Epidemiol 2001;15:34-9.

37. Betul Yakistiran et al. First trimester bleeding and pregnancy outcomes: case control study. International Journal of Women's Health and Reproduction Sciences, Vol. 4, No. 1, January 2016,4-7.

38. Strobino B, Pantel Silverman J. Gestational vaginal bleeding and pregnancy outcome. Am J Epidemiol 1989;129:806-15

39. IpekGurol-Urganci, David A Cromwell, Leroy C Edozien, Gordon CS Smith, ChidimmaOnwere, et al. (2011) Risk of placenta previa in second birth after rst birth cesarean section: a population-based study and meta-analysis BMC Pregnancy Childbirth 11: 95

40. Han CS, Schatz F, Lockwood CJ (2011) Abruptionassociated prematurity. ClinPerinatol 38: 407-421.

41. Ananth, C.V., Berkowitz, G.S., Savitz, D.A. and Lapinski, R.H. (1999) Placental Abruption and Adverse PerinatalOutcomes. JAMA, 282, 1646-1651

42. Vahanian, S.A., Lavery, J.A., Ananth, C.V. and Vintzileos, A. (2015) Placental Implantation Abnormalities and Risk of
Preterm Delivery: A Systematic Review and Metaanalysis. American Journal of Obstetrics and Gynecology, 213, S78S90. http://dx.doi.org/10.1016/j.ajog.2015.05.058

43. Bhandari, S., Raja, E., Shetty, A. and Bhattacharya, S. (2014) Maternal and Perinatal Consequences of Antepartum Haemorrhage of Unknown Origin. BJOG: An International Journal of Obstetrics andGynaecology, 121, 44-52. http://dx.doi.org/10.1111/1471-0528.12464

44. Corchia, C., Ferrante, P., Da Frè, M., Di Lallo, D., Gagliardi, L., Carnielli, V., Miniaci, S., Piga, S., Macagno, F. and Cuttini, M. (2013) Cause-Specific Mortality of Very Preterm Infants and Antenatal Events. Journal of Pediatrics, 162 ,

$1125-1132$ http://dx.doi.org/10.1016/j.jpeds.2012.11.093

45. Gouyon, J.-B., Vintejoux, A., Sagot, P., Burguet, A., Quantin, C. and Ferdynus, C. (2010) Neonatal Outcome Associ- ated with Singleton Birth at 34-41 Weeks of Gestation. International Journal of Epidemiology, 39, 769776. http://dx.doi.org/10.1093/ije/dyq037

46. Phaloprakarn, C., Manusirivithaya, S. and Boonyarittipong, P. (2015) Risk Score Comprising Maternal and Obstetric Factors to Identify Late Preterm Infants at Risk for Neonatal Intensive Care Unit Admission Journal of Obstetrics and Gynaecology Research, 41, 680-688. http://dx.doi.org/10.1111/jog.12610

47. Scheuchenegger, A., Lechner, E., Wiesinger-Eidenberger, G., Weissensteiner, M., Wagner, O., Schimetta, W. and Resch, B. (2014) Short-Term Morbidities in Moderate and Late Preterm Infants. KlinischePädiatrie, 226, 216-220.

48. Sun L, Tao F, Hao J, Su P, Liu F, Xu R. First trimester bleeding and adverse pregnancy outcomes among Chinese women: from a large cohort study in China. J MaternalFetal Neonatal Med. 2012; 25(8):1297-1301. doi:10.3109/14767058.2011.632034.

49. Juan Yang, Katherine E. Hartmann, David A. Savitz, Amy H. Herring, Nancy Dole, Andrew F. Olshan, John M. Thorp, Jr.; Vaginal Bleeding during Pregnancy and Preterm Birth. Am J Epidemiol 2004; 160 (2): 118-125. doi: 10.1093/aje/kwh180

50. Williams M, Hickok D, Zingheim R, et al. Low birthweight and preterm delivery in relation to early-gestation vaginal bleeding and elevated maternal serum alpha-fetoprotein. ObstetGynecol 1992; 80:745-9.

51. Jouppila P. Vaginal bleeding in the last two trimesters of pregnancy. A clinical and ultrasonic study. ActaObstetGynecolScand 1979;58:461-7.

52. Velez Edwards DR, Baird DD, Hasan R, Savitz DA, Hartmann KE. First trimester bleeding characteristics associate with increased risk of preterm birth: data from a prospective pregnancy cohort. Hum Reprod. 2012; 27(1):54-60. doi:10.1093/humrep/der354.

53. French JI, McGregor JA, Draper D, et al. Gestational bleeding, bacterial vaginosis, and common reproductive tract infections: risk for preterm birth and benefit of treatment. ObstetGynecol 1999; 93:715-24.

54. Alexander JD, Schneider FD. Vaginal bleeding associated with pregnancy. Prim Care 2000; 27:137-51.

55. Tuzovic L, Djelmis J, Ilijic M. Obstetric risk factors associated with placenta previa development: case-control study. Croat Med J 2003; 44:728-33.

Source of Support: None Declared Conflict of Interest: None Declared 